\title{
Simulation of Thermal Conductivity of Polymer Nanocomposites, Using Models Based on Thermal-Electrical Analogy
}

\author{
E. A. Lysenkov
}

Petro Mohyla Black Sea National University,

10, 68 Desantnykiv Str.,

UA-54003 Mykolayiv, Ukraine

Some theoretical models of thermal conductivity of the polymeric nanocomposites based on thermoelectric analogy are proposed, and their accordance with experimental results are analysed for the polymer-carbon nanotubes (CNT) systems. The specificity of thermal conductivity of the polymer-CNT systems chosen for modelling is in the presence of a percolation transition, which is not taken into account by majority of thermalconductivity models. Therefore, using the thermoelectric analogy, we used models that well describe the percolation behaviour of the electrical conductivity of polymer-CNT systems, namely the Bruggeman's model, the Fourier model, and the scaling model, and applied these models to describe the thermal conductivity. As established, a model based on the theory of effective medium (the Bruggeman's model) does not take into account the existence of a percolation threshold at low CNT content and cannot be used for accurate description of experimental data. As discovered, the Fourier model demonstrates a good accordance with an experiment, however, it is applicable only for the systems, in which a large increase of thermal conductivity under reaching the percolation threshold is observed; these are systems with low own conductivity. As shown, the best accordance with experimental data is demonstrated within the scaling model that, besides the percolation threshold, takes into account the structural characteristics of clusters, which are formed by carbon nanotubes.

Запропоновано деякі теоретичні моделі теплопровідности полімерних нанокомпозитів, що базуються на термоелектричній аналогії, та проаналізовано відповідність їх експериментальним результатам для систем полімер-вуглецеві нанотрубки (ВНТ). Особливістю теплопровідности систем полімер-ВНТ, обраних для моделювання, є наявність перколяційного переходу, що більшість моделів теплопровідности не враховує. Тому, грунтуючись на термоелектричній аналогії, ми використали моделі, які добре описують перколяційну поведінку електропровіднос- 
ти систем полімер-ВНТ, а саме, моделі Бруг'гемана, Фур'є та скейлінгів модель, і застосували ці моделі для опису теплопровідности. Встановлено, що модель, який грунтується на теорії ефективного середовища (модель Бруг'емана), не враховує наявности порогу перколяції за низького вмісту ВНT і не може використовуватися для точного опису експериментальних даних. Виявлено, що модель Фур'є демонструє гарну відповідність експерименту, проте застосовний лише для систем, для яких спостерігається великий стрибок теплопровідности при досягненні порогу перколяції, тобто систем з низькою власною провідністю. Показано, що найкращу відповідність експериментальним даним демонструє скейлінгів модель, який, окрім порогу перколяції, враховує структурні характеристики кластерів, які формуються з вуглецевих нанотрубок.

Предложены некоторые теоретические модели теплопроводности полимерных нанокомпозитов, основанные на термоэлектрической аналогии, и проанализировано их соответствие экспериментальным результатам для систем полимер-углеродные нанотрубки (УНТ). Особенностью теплопроводности систем полимер-УНТ, выбранных для моделирования, является наличие перколяционного перехода, который большинство моделей теплопроводности не учитывает. Поэтому, основываясь на термоэлектрической аналогии, мы использовали модели, которые хорошо описывают перколяционное поведение электропроводности систем полимер-УНТ, а именно, модели Бруггемана, Фурье и скейлингову модель, и применили эти модели для описания теплопроводности. Установлено, что модель, которая основываются на теории эффективной среды (модель Бруггемана), не учитывает существования порога перколяции при низком содержании УНТ и не может использоваться для точного описания экспериментальных данных. Выявлено, что модель Фурье демонстрирует хорошее соответствие эксперименту, однако применима только для систем, для которых наблюдается большой скачок теплопроводности при достижении порога перколяции, то есть систем с низкой собственной проводимостью. Показано, что наилучшее соответствие экспериментальным данным демонстрирует скейлингова модель, которая, кроме порога перколяции, учитывает структурные характеристики кластеров, формирующихся из углеродных нанотрубок.

Key words: percolation behaviour, polymer nanocomposites, thermal conductivity, carbon nanotubes, thermal-electrical analogy.

Ключові слова: перколяційна поведінка, полімерні нанокомпозити, теплопровідність, вуглецеві нанотрубки, теплоелектрична аналогія.

Ключевые слова: перколяционное поведение, полимерные нанокомпозиты, теплопроводность, углеродные нанотрубки, теплоэлектрическая аналогия.

(Received 22 May, 2019; after revision 26 December, 2019) 


\section{INTRODUCTION}

Polymer nanocomposites filled with carbon nanotubes (CNT) are the subject of intense research over the past years. A great interest in the study of systems of this type is associated with their wide application for the production of polymeric materials with improved functional characteristics [1-3]. As a result of a large number of experimental studies of a variety of polymeric nanocomposites filled with CNT, a number of materials with unique properties have already been obtained due to the combination of polymer and nanofiller characteristics [4, 5]. Most of the polymeric nanocomposites are characterized by percolation behaviour, which manifests itself in the sharp increase in properties when introducing some critical concentrations of filler and is associated with the formation of a percolation cluster. Due to the high thermal conductivity of CNT, which are characterized by highly anisometric forms, nanocomposites on their base also exhibit a high thermal conductivity at small fillings [6].

However, for most of the investigated polymer-CNT systems, no percolation jump is observed [7]. The reason for this is the presence of the boundary thermal resistance between the nanotubes and the polymer matrix, which limits the heat flow in nanocomposites filled with CNT. Nevertheless, there are works where the step-like increase of thermal conductivity is observed when reaching the critical concentrations of filler [6,8].

Mathematical and computer simulations are widely used to predict the thermal conductivity of polymer nanocomposites, but existing models are not universally versatile and have their limitations. There are a few models, which can describe the percolation increase in the thermal conductivity [6,9]. However, there are many models, which describe percolation behaviour of electrical conductivity of polymer nanocomposites [10]. As known, two systems are analogous when they are mathematically equivalent, i.e., the governing equations are of the same type, as between diffusion and heat conduction, liquid flow and electric current flow. Therefore, thermal conductivity and electric conductivity are also equivalent [11]. For instance, the analogy between heat and electric conductions has already been used to solve complex steady state and transient heatconduction problems.

Therefore, the purpose of this work is to determine the possibility of use models based on thermal-electrical analogy to describe the experimental data of the thermal conductivity of polymer-CNT systems, for which percolation behaviour is observed. The selection of the optimal model will allow predicting the functional properties of polymer nanocomposite materials filled with CNT. 


\section{MODELS OF THERMAL CONDUCTIVITY BASED ON THERMAL-ELECTRICAL ANALOGY}

Several attempts have been made to predict the thermal conductivity of binary polymer composite systems by applying different theoretical models [12, 13]. However, there is still no such a general model that can be applied to predict accurately the conductivity for all the systems. In this regard, we should consider models well describing the behaviour of the electrical conductivity of polymerCNT systems and apply these models to simulate the thermal conductivity. According to [14, 15], the most frequently used models for simulating the electrical conductivity of such systems are the Bruggeman's model, the Fourier model, and the scaling model.

\subsection{The Modified Bruggeman's Model}

To describe the concentration dependence of electrical conductivity of filled heterogeneous composite systems, one can use the basic approaches of the effective medium theory and symmetrical Bruggeman's formula [16]. Using thermal-electrical analogy, Bruggeman's formula in the terms of thermal conductivity can be rewritten as follows:

$$
(1-\varphi) \frac{\left(\lambda-\lambda_{m}\right)}{2 \lambda+\lambda_{m}}+\varphi \frac{\left(\lambda-\lambda_{f}\right)}{2 \lambda+\lambda_{f}}=0,
$$

where $\lambda_{f}, \lambda_{m}$ and $\lambda$ are the thermal conductivities of filler, polymer matrix, and composite, respectively. This equation can be solved by determining $\lambda$, and then, we obtain [17]

$$
\lambda=\frac{1}{4}\left[\delta+\left(\delta^{2}+8 \lambda_{m} \lambda_{f}\right)^{\frac{1}{2}}\right]
$$

where $\delta=(3 \varphi-1) \lambda_{m}+(2-3 \varphi) \lambda_{f}$.

Some research [18] showed that there is a smaller deviation between the experimental data and the theoretical value of Bruggeman's model. The thermal conductivities of epoxy/silica, epoxy/alumina, and polyimide/aluminium nitride, based on the experimental data and Bruggeman's model, are in a good agreement when the volume fraction of fillers attains $40 \%$. For lower amounts of filler particles, Bruggeman's model is not valid.

Xue [19] modified Bruggeman's model and suggested the existence of two types of the volume content of filler particles, namely, the real $\left(\varphi_{0}\right)$ and the effective $(\varphi)$. The relation between $\varphi_{0}$ and $\varphi$ is written as follows: 


$$
\varphi=\alpha \varphi_{0},
$$

where $\alpha$ is the increasing factor and, at that, $\alpha>1$. This factor depends on the polymer and filler nature, on the particles' shape and sizes, the volume content and their space distribution.

Taking the Bruggeman's equation as the basis, Xue suggested that electrical conductivities of filler and matrix depend on the filler content. Assuming that all particles in a composite have a spherical shape, based on the Maxwell-Garnett theory, and correlation between two distinct topological structures (symmetrical and asymmetrical ones) [20], electrical conductivities of filler and matrix can be represented as in Ref. [19]. For thermal conductivity, this equation can be written as follows:

$$
\lambda_{f}^{b}=\frac{2 \varphi}{3-\varphi} \lambda, \lambda_{m}^{b}=\frac{2(1-\varphi)}{2+\varphi} \lambda_{m} .
$$

Substituting (3) and (4) into (1) [19, 20], we can obtain the equation for the calculation of the effective thermal conductivity of composite systems:

$$
\left(1-\alpha \varphi_{0}\right) \frac{\left(\lambda-\lambda_{m}^{b}\right)}{2 \lambda+\lambda_{m}^{b}}+\alpha \varphi_{0} \frac{\left(\lambda-\lambda_{f}^{b}\right)}{2 \lambda+\lambda_{f}^{b}}=0
$$

\subsection{The Fourier Model}

In Ref. [21], Fourier et al. have proposed the analytical model, which is based on the Fermi-Dirac distribution and describes the dielectric-conductor transition.

Using thermal-electrical analogy, the basic equation of this model can be rewritten as follows:

$$
\log (\lambda)=\log \left(\lambda_{f}\right)+\frac{\log \left(\lambda_{m}\right)-\log \left(\lambda_{f}\right)}{1+\exp \left[b\left(\varphi-\varphi_{c}\right)\right]},
$$

where $\lambda, \lambda_{f}, \lambda_{m}$ are the thermal conductivities of composite, filler, and polymer matrix, respectively; $\varphi$ is the filler content, $b$ is the empirical parameter, which leads to the change in the thermal conductivity of the system when reaching the percolation threshold $\varphi_{c}$.

In general, the Fourier model is very similar to the sigmoidal model [22] by both the ' $S$ '-like shape, which qualitatively corresponds to a typical percolation curve, and the influence of most parameters on the value of the total thermal conductivity of the system. The main variable parameter of Fourier model is the parameter 
$b$, which changes the shape of the curve.

\subsection{The Scaling Model}

The scaling model assumes that the appearance of high thermal conductivity is explained by the probability of formation of the contact between the filler particles within the composite [23]. The basic equation of this model is the power law, which is written as follows:

$$
\lambda \propto\left(\varphi-\varphi_{c}\right)^{k},
$$

where $\lambda$ is the thermal conductivity of the nanocomposite, $\varphi$ is the filler volume fraction, $\varphi_{c}$ is the percolation threshold, i.e., the minimum filler content, at which a continuous cluster of particles is formed, $k$ is the critical thermal-conductivity index, which mainly depends on the topological dimension of the system and does not depend on the structure of particles, which form clusters, and their interaction.

However, Eq. (7) allows defining the thermal conductivity only after the percolation threshold. To expand the application range of this model, Efros and Shklovskii for electric conductivity [24] as well as Sun et al. [9] for thermal conductivity have proposed to use not one scaling equation, but the set of equations of the type

$$
\lambda=\left\{\begin{array}{l}
\lambda_{m}\left(\varphi-\varphi_{c}\right)^{k} \text { for } \varphi>\varphi_{c}, \\
\lambda_{f}\left(\varphi_{c}-\varphi\right)^{-q} \text { for } \varphi<\varphi_{c},
\end{array}\right.
$$

where $\lambda, \lambda_{m}, \lambda_{f}$ are the thermal conductivities of composite, matrix, and filler, respectively, $q$ is the critical thermal-conductivity index characterizing the number of particles, which form the percolation cluster. This set of equations is a universal one and allows describing the thermal conductivity of filled polymer systems in the vicinity of the percolation transition with a high degree of accuracy.

\section{RESULTS AND DISCUSSION}

The experimental results of the concentration dependence of the thermal conductivity for polyethyleneoxide (PEO-10000)-CNT [25], crosslinked polyurethane (CPU)-CNT [26], polyethylene (PE)-CNT [27] systems were used to establish the correspondence between the theoretical models and the experiment.

In general, the Bruggeman's model (Eq. (1)) provides a sharp change in thermal conductivity when certain filler content is reached, but the value of this concentration is fixed and equal to 
$1 / 3$ of the volume fraction. This model gives only a qualitative description of the behaviour of thermal conductivity for such transitions.

The main disadvantages of the Bruggeman's model were eliminated in the work of Xue, which has proposed the modified Bruggeman's model. Using the thermal-electric analogy, we propose to rewrite Xue's equation in the terms of thermal conductivity. As seen from the analysis of the results of simulation of the thermal conductivity for the polymer-CNT systems using the modified Bruggeman's model represented in Fig. 1, the modified Bruggeman's model provides a good match between the numerical calculations and the experiment at low filler concentrations. Introduction to the model of the increasing factor $\alpha$ gives the possibility to shift the region of a sharp change in the thermal conductivity towards lower concentrations (much less than 1/3 for the original Brug-
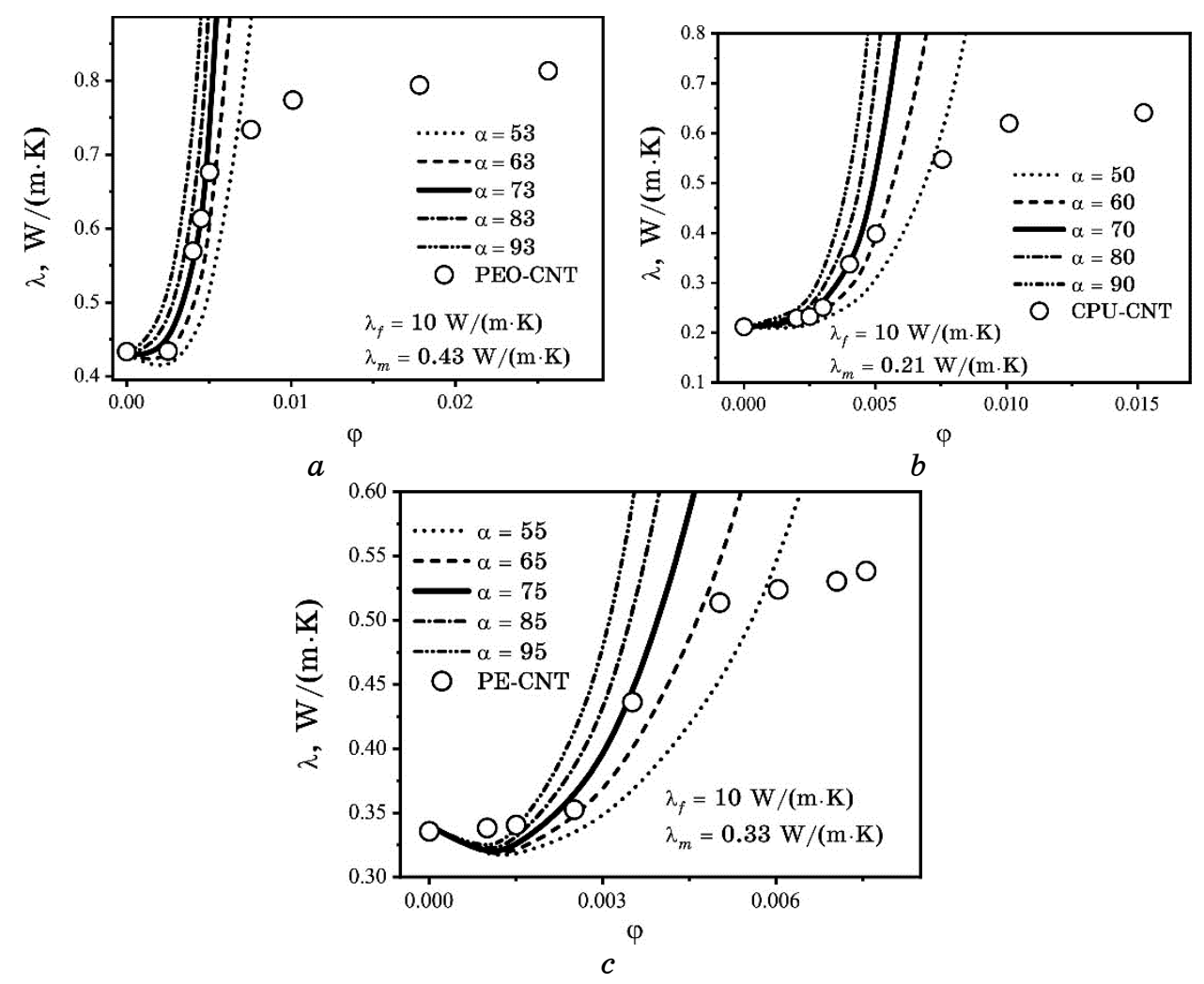

Fig. 1. The experimental data simulated using Eq. (5) for nanofilled systems based on PEO-10000 (a), CPU $(b)$, and PE $(c)$. Solid lines correspond to the modified Bruggeman's model. 
geman's model). This, in fact, allows compensating the absence of the percolation threshold in this model. However, the modified Bruggeman's model describes poorly the change in the thermal conductivity at concentrations higher than the percolation threshold. In essence, this model describes only half the percolation curve of thermal conductivity responsible for forming a percolation cluster. Further processes of growth of the percolation cluster and its influence on the thermal conductivity of the system are not considered by the Bruggeman's model and, therefore, cannot correctly describe the properties, which exhibit percolation behaviour.

In Figure 2 we show the modelling of the experimental data for the polymer-CNT system by using the Fourier model. The shape of the Fourier model curve depends significantly on its parameters [14]. Thus, by gradually varying the percolation threshold, the thermal conductivity is changed at lower filler concentrations, and
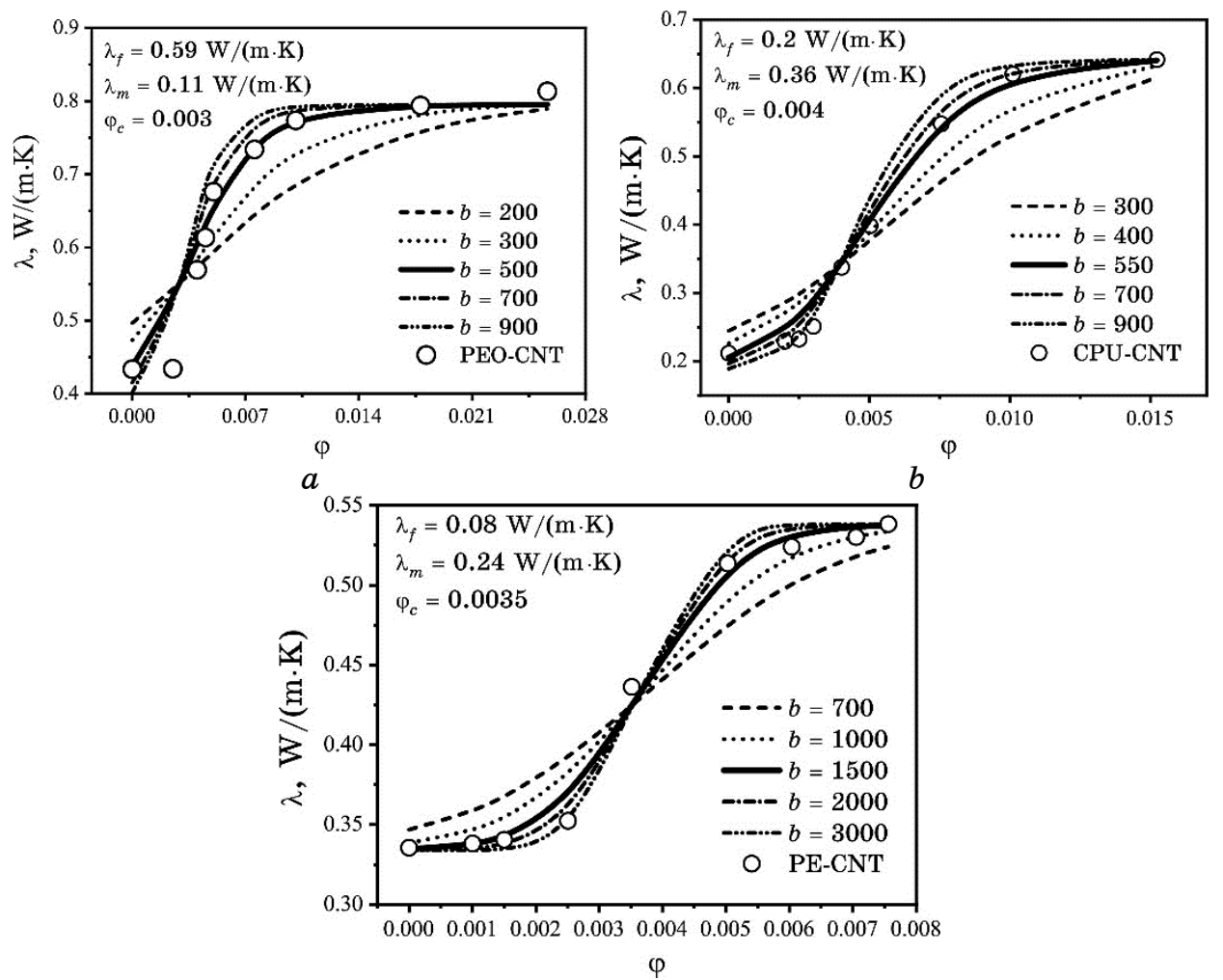

$c$

Fig. 2. The experimental data simulated using Eq. (6) for nanofilled systems based on PEO-10000 (a), CPU $(b)$, and PE $(c)$. Solid lines correspond to the Fourier model. 
the maximum value of the system thermal conductivity can be achieved for any value of $\varphi_{c}$. Therefore, the value of $\varphi_{c}$ substantially influences the maximum thermal conductivity of the nanocomposite. The value of filler thermal conductivity also influences the maximum thermal conductivity of the system. The system conductivity increases with increasing filler conductivity.

This model describes well enough the experimental data on the thermal conductivity of the polymer-CNT systems (see Fig. 2). It allows determining the value of the percolation threshold for polymer-CNT systems. Thus, the values of percolation threshold defined by the Fourier model are $0.003,0.004$ and 0.0035 for systems based on PEO, CPU, and PE, respectively. However, to fit the function (6), the values of the parameters $\lambda_{f}$ and $\lambda_{m}$ were substantially lower as compared with the intrinsic thermal conductivities of the CNT and polymer matrix. This is especially applying to the thermal conductivity of carbon nanotubes, which, according to the literature data, is of $1-3 \mathrm{~kW} / \mathrm{m} \cdot \mathrm{K}$ [28]. This significantly decreases the accuracy of the model and limits its application. Such a discrepancy is explained by a small jump of the thermal conductivity when passing through the percolation threshold in the polymer-CNT systems. The authors of a given model described the results of the electrical conductivity for the systems, in which the leap of the electrical conductivity equal to 10-11 orders of magnitude was observed [21].

Using the thermal-electric analogy, we propose to rewrite scaling equation in the terms of thermal conductivity. Figure 3 illustrates the simulation of the experimental data for the polymer-CNT system with using the scaling model. As seen from the analysis of functions (8) (see Fig. 3), the thermal conductivity of the system increases with decreasing critical index $k$, and a decrease in the critical index $q$ leads to the decrease in the system thermal conductivity. After analysing the system of Eqs. (8), we can say that, as for the electrical conductivity, change in the value of the critical index $k$ does not lead to the change in the maximum thermal conductivity of the polymer composite, which is specified only by the filler thermal conductivity. The change in the percolation threshold of filler in the composite does not result in the change of the system thermal conductivity.

The scaling model demonstrates a good correspondence with the experimental data of the thermal conductivity for the polymer-CNT systems (Fig. 3). Theoretically, for electrical conductivity, scaling model assumes that the critical indexes are universe for the systems with the same dimensions. However, the physical content of thermal-conductivity critical indexes is not established. This requires deep development of the scaling model, using thermal-electrical analogy of polymer nanocomposites. 

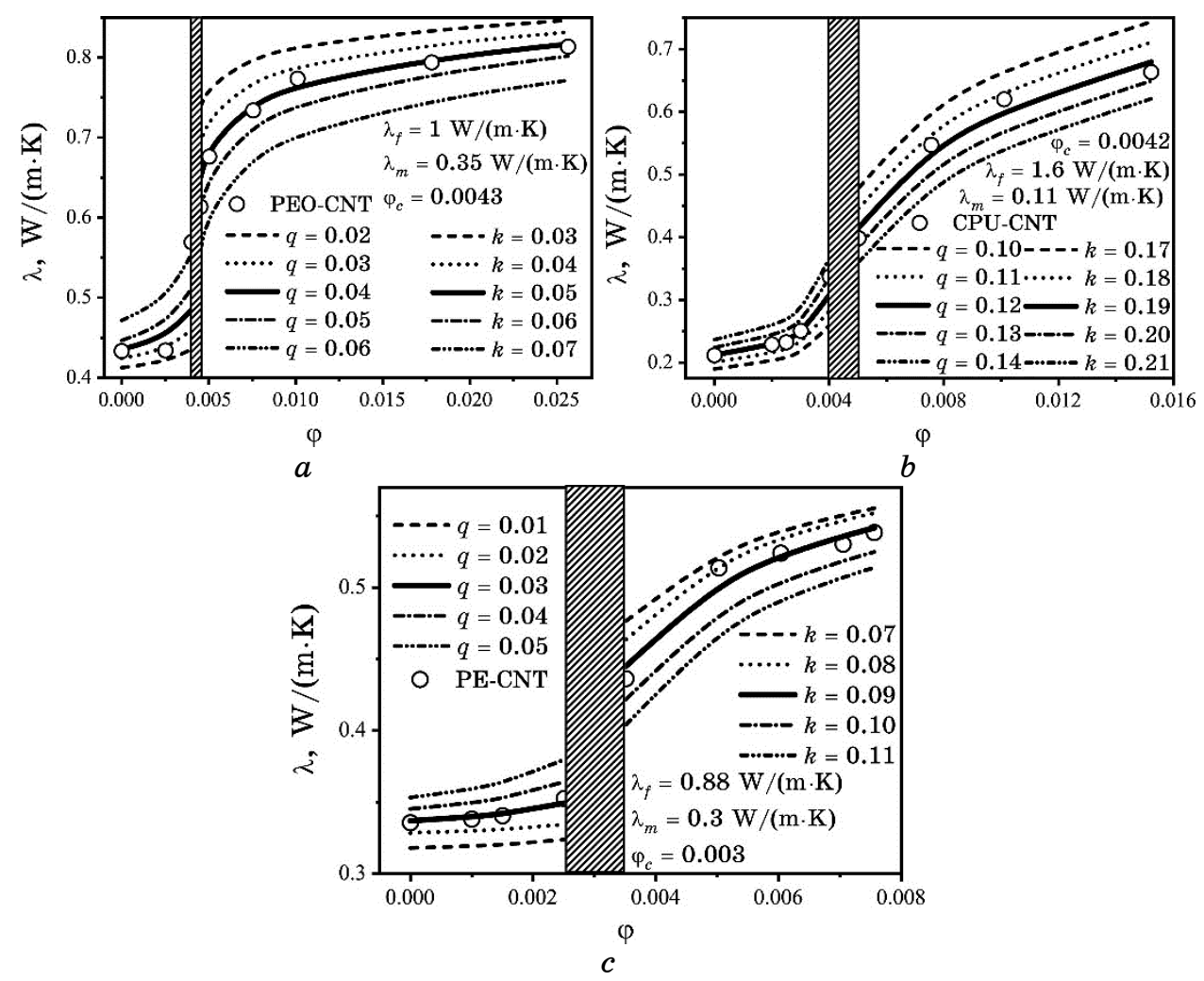

Fig. 3. The experimental data simulated using equation (8) for nanofilled systems based on PEO-10000 (a), CPU (b), and PE (c). Shaded area is the percolation threshold region, and lines correspond to the scaling model.

\section{CONCLUSIONS}

As a result of this work, we have analysed the basic theoretical models based on thermal-electrical analogy of polymer nanocomposites and the possibility of their application for the description of the experimental data for polymer-CNT systems. As established, the models based on the provisions of the effective medium theory describe poorly the experimental data. This is explained by the fact that these models (Bruggeman's and Xue's ones) do not take into account the presence of the percolation threshold. As revealed, the Fourier model, whose graph is the classical logistic sigmoidal function, describes well enough the experimental data of thermal conductivity of the polymer-CNT systems. However, this model is not suitable for describing systems on the base of polymer matrixes with high intrinsic thermal conductivity because of a low thermal 
conductivity in the percolation transition. As shown, the model, which is based on the scaling approach for describing properties of the structurally nonuniform systems, demonstrates a good correspondence with the experimental data. This model accounts the presence of the percolation threshold, at which the functions have discontinuity at infinity. The advantage of this model is the accounting of the structural features of the percolation-cluster formation, which are expressed through the universal critical indexes $k$ and $q$. However, the physical content of thermal-conductivity critical indexes is not established. Therefore, from all the theoretical models describing the percolation behaviour of electrical conductivity, only a scaling model can correctly describe the jump-like behaviour of the thermal conductivity of polymer-CNT systems. The main reason for the incorrect application of other models is a small, as compared with electrical conductivity, jump of thermal conductivity when reaching the threshold of percolation.

\section{REFERENCES}

1. L. Rodríguez-Tembleque, E. García-Macías, and A. Sáez, Composites Part B: Engineering, 154: 114(2018); https://doi.org/10.1016/j.compositesb.2018.08.003.

2. R. K. Prusty, D. K. Rathore, and B. C. Ray, Advances in Colloid and Interface Science, 240: 77 (2017); https://doi.org/10.1016/j.cis.2016.12.008.

3. M. Brailo, A. Buketov, S. Yakushchenko et al., Materials Performance and Characterization, 7, No. 1: 275 (2018); https://doi.org/10.1520/MPC20170161.

4. H. Tanabi and M. Erdal, Results in Physics, 12: 486 (2019); https://doi.org/10.1016/j.rinp.2018.11.081.

5. A. V. Buketov, O. O. Sapronov, M. V. Brailo et al., Materials Science, 49, No. 5: 696 (2014); https://doi.org/10.1007/s11003-014-9664-0.

6. S. Y. Kwon, I. M. Kwon, Y.-G. Kim et al., Carbon, 55: 285 (2013); https://doi.org/10.1016/j.carbon.2012.12.063.

7. Z. Han and A. Fina, Progress in Polymer Science, 36: 914 (2011); https://doi.org/10.1016/j.progpolymsci.2010.11.004.

8. P. C. Ma, B. Z. Tang, and J.-K. Kim, Carbon, 46: 1497 (2008); https://doi.org/10.1016/j.carbon.2008.06.048.

9. K. Sun, Z. D. Zhang, L. Qian et al., Appl. Phys. Lett., 108: 061903 (2016); https://doi.org/10.1063/1.4941758.

10. R. Vargas-Bernal, G. Herrera-Pérez, M. E. Calixto-Olalde, and M. TecpoyotlTorres, J. Electric. and Comput. Engin., 2013: 179538 (2013); http://dx.doi.org/10.1155/2013/179538.

11. X. T. Cheng and X. G. Liang, Intern. J. Heat and Mass Transfer, 131: 709 (2019); https://doi.org/10.1016/j.ijheatmasstransfer.2018.11.111.

12. K. Pietrak and T. S. Wisniewski, J. of Power Technol., 95, No. 1: 14 (2015); http://papers.itc.pw.edu.pl/index.php/JPT/article/view/463.

13. M.-X. Shen, Y.-X. Cui, J. He et al., International Journal of Minerals, Metallurgy and Materials, 18, No. 5: 623 (2011); https://doi.org/10.1007/s12613-011-0487-9. 
14. E. A. Lysenkov and V. V. Klepko, J. of Nano-Electron. Phys., 8, No. 1: 01017 (2016); https://doi.org/10.21272/jnep.8(1).01017.

15. R. Taherian, M. J. Hadianfard, and A. N. Golikand, J. Appl. Polym. Sci., July: 1497 (2012); https://doi.org/10.1002/APP.38295.

16. D. A. G. Bruggeman, Ann. Phys., 24: 636 (1935); https://doi.org/10.1002/andp.19354160705.

17. A. A. Snarskii, Phys. Usp., 50: 1239 (2007); https://doi.org/10.1070/PU2007v050n12ABEH006348.

18. J. R. Chu, X. H. Zhang, and C. X. Xu, Polym. Mater. Sci. Eng., 4: 17 (2000); http://en.cnki.com.cn/Article_en/CJFDTotal-GFZC200004004.htm.

19. Q. Xue, Physica B, 325: 195 (2003); https://doi.org/10.1016/S09214526(02)01523-5.

20. Y. Q. Ma and Z. Y. Li, Acta Phys. Sinica, 39: 458 (1990); http://wulixb.iphy.ac.cn/CN/Y1990/V39/I3/457.

21. J. Fourier, G. Boiteax, G. Seytre et al., Synth. Met., 84: 839 (1997); https://doi.org/10.1016/S0379-6779(96)04173-2.

22. R. Taherian, ECS J. of Solid State Sci. and Tech., 3, No. 6: M26 (2014); https://doi.org/10.1149/2.023406jss.

23. S. Kirkpatrick, Phys. Rev. Lett., 27: 1722 (1971); https://doi.org/10.1103/PhysRevLett.27.1722.

24. A. L. Efros and B. I. Shklovskii, physica status solidi (b), 76, No. 2: 475 (1976); https://doi.org/10.1002/pssb.2220760205.

25. E. A. Lysenkov and V. V. Klepko, J. of Engin. Phys. and Thermophys., 88, No. 4: 1008 (2015); https://doi.org/10.1007/s10891-015-1278-3.

26. E. A. Lysenkov, Z. O. Gagolkina, E. V. Lobko et al., Funct. Mater., 22, No. 3: 342 (2015); http://dx.doi.org/10.15407/fm22.03.342.

27. R. V. Dinzhos, N. M. Fialko, and E. A. Lysenkov, J. of Nano- Electron. Phys., 6, No. 1: 01015 (2014); https://jnep.sumdu.edu.ua/uk/component/search/index.php?option=com_co ntent\&task=full_article\&id $=\mathbf{1 1 8 5}$.

28. D. D. L. Chung, Appl. Therm. Eng., 21: 1593 (2001); https://doi.org/10.1016/S1359-4311(01)00042-4. 